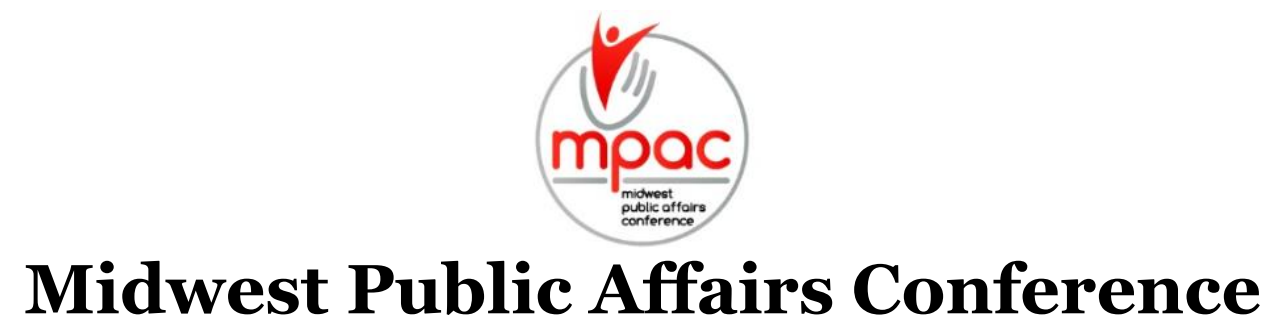

www.MidwestPAC.com

\title{
Board of Trustees
}

President

Michael Ford, University of Wisconsin - Oshkosh

Vice President

Stephen Kleinschmit, University of Illinois Chicago

Secretary and Treasurer

Max Mendieta, University of Michigan - Flint

Editor-in-Chief, Journal of Public and Nonprofit Affairs

Deborah A. Carroll, University of Illinois Chicago

Representative Designate

Dagney Faulk, Ball State University

ASPA National Council Representative

J. Paul Blake, University of Washington

The Journal of Public and Nonprofit Affairs (ISSN: 2381-3717) is published by the Midwest Public Affairs Conference under the Creative Commons Attribution 3.0 (CC BY) License. No responsibility for the views expressed by the author(s) in the journal is assumed by the editor(s) or the publisher, the Midwest Public Affairs Conference. Any errors within the manuscripts remain the responsibility of the author(s).

Those wishing to submit a manuscript for publication consideration in the journal should follow the submission instructions and guidelines available at: www.jpna.org. Author(s) must submit their manuscripts electronically through the website. If you have not previously registered with the journal, you will need to register as an author and then follow the instructions on the screen for submission. 